\title{
A mediating role of social capital between corporate social responsibility and corporate reputation: Perception of local university on CSR of KHNP
}

\author{
Jae-Hun JOO*
}

Received: January 30, 2020 Revised: February 28, 2020 Accepted: March 05, 2020.

\begin{abstract}
Purpose: Most of all studies regarding corporate social responsibility have been dealing with its direct performance. Many previous studies provided the evidence that corporate social responsibility activities directly affect firms' competitiveness or corporate reputation. However, there are no studies regarding the role of social capital between corporate social responsibility and firms' competitiveness. The present study aims to examine a mediating role of social capital between corporate social responsibility and corporate reputation. Research design, data and methodology: The structural equation model integrating corporate social responsibility, social capital, and corporate reputation was proposed with three hypotheses. Questionnaire including 15 question items for three concepts was designed. Data for testing hypotheses were collected from students and staff who had experienced the social responsibility activities of Korea Hydro \& Nuclear Co. Ltd. SPSS and SmartPLS were used to analyze data. Results: All three hypotheses were supported at the significance level of 0.01 . Corporate social responsibility have a significant influence on social capital as well as corporate reputation. Social capital plays a mediating role in the relationship between corporate social responsibility and corporate reputation. Conclusions: The present paper identified a missing link between corporate social responsibility and corporate reputation by validating an indirect effect of corporate social responsibility on corporate reputation through social capital. The present study contributes to finding the indirect link between corporate social responsibility and corporate reputation. Implications for academics and practitioners. The research model can be extended to analyze the relationship between corporate social responsibility and its performance. The present study sheds light on identification of a new role of social capital. Managers of firms have the opportunity to recognize the fact that investment recovery of corporate social responsibility results from social capital and corporate reputation in long-term rather than short-term. The results of this study offers an insight that managers can enhance customer loyalty. The process linking corporate social responsibility to corporate reputation through social capital implies that firms can realize spiritual marketing delivering authentic storytelling through corporate social responsibility. The present study has a limitation for generalizing of research results because the sampling came from a case of firm.
\end{abstract}

Keywords: Corporate Social Responsibility, Social Capital, Corporate Reputation, Spiritual Marketing, KHNP.

JEL Classification Code: M10, M14, L21

\section{1. 서론}

기업의 사회적 책임(Corporate Social Responsibility. CSR)에 대한 많은 연구가 수행되어 왔다(Ahmadian \& Khosrowpour, 2017; Carroll, 1991; Cho, et al, 2019; Nguyen, \& Tu, 2019). 오늘날 CSR 은 사회공헌 차원을 넘어서 기업 경쟁력을 높이는 투자 활동으로 보고 있다(Cochran, 2007).

*First Author and Corresponding Author: Professor, Department of Information Management, Dongguk University-Gyeongju, South Korea, Email: givej@dongguk.ac.kr

๑) Copyright: Korean Distribution Science Association (KODISA)

This is an Open Access article distributed under the terms of the Creative Commons Attribution NonCommercial License (https://creativecommons.org/licenses/by-nc/4.0/) which permits unrestricted noncommercial use, distribution, and reproduction in any medium, provided the original work is properly cited.
Cochran(2007)의 주장에 따르면, 이해관계자이론 관점에서 CSR 활동이 기업의 내외부 이해관계자인 종업원·고객·정부·언론기관 등을 통해서 기업 경쟁력에 영향을 주며, 궁극적으로는 기업 이익에 긍정적 영향을 미치기도 한다. CSR 을 기업의 투자 활동으로 본다면, 결국 투자 성과를 고려할 수밖에 없다. CSR 활동에 대한 성과(corporate social performance)에 대한 연구는 Sethi(1975)에서 시작하여 Caroll (1979)과 Wartick and Cochran (1985) 등에 의해 확장되어 왔다.

$\mathrm{CSR}$ 과 기업 성과 간의 관계 대한 많은 연구가 수행되어왔지만 일치된 연구결과를 보이는 것은 아니다(Kin \& Lee, 2013; Joo et al, 2014). 전략적 CSR 활동은 기업에 경쟁우위를 제공한다(Hillman \& Kein, 2001; Ahmadian \& Khosrowpour, 2017). CSR 활동은 장기적 관점에 이해관계자들에게 
혜택을 제공하는데, 거래적(transactiona)이라기보다는 관계적(relational) 혜택을 제공한다(Ahmadian \& Khosrowpour, 2017). Ahmadian and Khosrowpour(2017)의 연구에 따르면, 관계적이라는 의미는 CSR 활동이 기업에 장기적인 평판(reputation)과 충성도라는 혜택을 가져다준다는 것이다. 소비자들이 점차 환경을 더욱 의식하는 오늘날, CSR 활동은 브랜드 평판과 고객 충성도라는 장기적 가치를 제공하는 역할을 한다(Ahmadian \& Khosrowpour, 2017). 또한 CSR 활동을 잘 하는 기업은 실수나 스캔들에 관련된 경우에도 기업 평판에 대한 부정적 영향이 줄어든다(Minor \& Morgan, 2011). 기업 평판은 기업 성과의 중요한 척도가 된다. 또한 CSR 은 기업 차별화 전략의 핵심이 될 수 있다(McWilliams et al, 2006). CSR 이 제품 특성이나 생산과정에 직접 영향을 미치지 않는 경우라 하더라도, CSR 은 기업 평판을 형성하여 유지하는데 기여한다(McWilliams et al, 2006). 따라서 기업 평판은 CSR 활동의 중요한 성과라 할 수 있다.

많은 연구에서 CSR 활동이 기업 평판에 긍정적 영향을 준다는 사실은 이미 밝혀졌다(Ahmadian \& Khosrowpour, 2017; McWilliams et al, 2006). 그러나 CSR 과 기업 평판 간의 직접적인 관계 외에도 아직 밝혀지지 않은 다른 연결고리가 있는가에 대한 연구는 수행된 바가 없다. 즉, CSR 활동이 기업의 평판에 직접적으로 영향을 주기도 하지만, 어떤 다른 경로를 통해 기업 평판에 영향을 줄 수도 있다. CSR 활동과 기업 평판 간의 아직 규명되지 않은 관계를 밝힌다면, 기업의 투자활동으로써의 $\mathrm{CSR}$ 의 역할은 물론이고 기업 성과 향상의 새로운 전략적 대안을 제시하는데도 기여하게 될 것이다.

따라서 본 연구는 기업 평판에 대한 CSR 활동의 직접적인 영향 관계와 더불어 간접적 영향 경로를 밝히는데 있다. 본 연구에서 사회적 자본 이론(social capital theory)을 기반으로 CSR 활동과 기업 평판의 관계를 분석한다. 즉, $\mathrm{CSR}$ 활동이 사회적 자본을 통해 기업 명성에 긍정적 영향을 주는 경로, 즉 CSR 과 기업 평판 간의 관계에서 사회적 자본의 매개역할을 규명하고자 한다. 본 연구는 CSR 활동, 사회적 자본, 기업 평판 간의 관계를 구조방정식모형(structural equation modelling)으로 표현하여 설문조사를 통해 연구가설을 검증한다.

한국수력원자력(주)(이하에서는 한수원이라 함)은 경주지역의 대표적인 공기업이다. 본 연구는 한수원의 CSR 활동에 대한 지역 대학(학생과 직원)을 중심으로 설문조사를 통해 연구가설을 검증한다.

\section{2. 이론적 배경}

\subsection{CSR 과 기업 평판}

$\mathrm{CSR}$ 이란 기업이 적정 이익을 창출하고 법률을 준수하면서 윤리적 및 사회적으로 지지받을 수 있는 경영 관련 활동인데, 일반적으로 경제적, 법률적, 윤리적, 재량적(또는 자선적) 책임으로 분류된다(Camoll, 1979, 1991). 대부분의 CSR 연구에서 CSR 활동이 경제적 성과에 긍정적 영향을 미치는 것으로 나타나고 있으나, 일부 연구에서는 그렇지 않는 것으로 나타나고 있다(Kim \& Lee, 2014; Kim \& Youn, 2019; Park, 2019). Kim \& Lee (2014)은 CSR 과 경제적 성과 간에 일관된 연구 결과가 나타나지 않는 이유로 연구방법론 상의 문제, CSR 범주의 문제, 경제적 성과의 자료 문제, 표본 문제 등을 들고 있다.

Joo et al. (2017)에서는 CSR을 비즈니스 생태계를 가꾸기 위한 투자로 보았다. CSR 활동이 기업 성과에 직접적인 영향을 주는 경제적 가치 창출 효과 외에도 사회적 가치 창출을 통한 지속가능한 비즈니스 생태계에 영향을 미치고, 이는 다시 지속가능한 비즈니스 생태계의 참여기업의 성과(경쟁력 또는 경쟁우위)에 영향을 준다고 하였다(Joo et al, 2017).

한수원은 봉사활동, 교육 및 장학지원사업, 지역경제협력사업, 주변환경개선사업, 지역복지사업, 지역무역진흥사업 등으로 지역사회에 공헌하고 있다. 구체적으로는 한수원 사회봉산단, 민들레홀씨기금, 행복더함 희망나래, 안신가로등, 글로벌봉사단 등을 운영하고 있다. 특히, 한수원은 2016 년부터 지역대학생을 모집하여 개도국 어려운 이웃의 친구로서 주거환경 개선, 교육 및 문화활동 등을 통해 해당국가 사회문제 해결에 기여하고 있다(Lim \& Park, 2018).

Fombrun and van Rie(1997)은 기업 평판을 경제적, 전략적, 마케팅, 조직적, 사회학적, 회계적 관점에서 살펴보고, 종합적 관점에서 다음과 같이 정의하였다. 기업 평판이란 이해관계자들에게 가치있는 결과를 전달할 수 있는 능력을 나타내는 것으로 기업의 과거 행동과 그 결과에 대한 종합적인 평가이다Fombrun \& Rindova, 1996; Fombrun \& van Riel, 1997). 기업 평판은 경쟁적 산업 환경에서 기업 내부의 직원과 외부의 이해관계자들에게 그 기업의 상대적 지위를 측정할 수 있게 해주는 방편이 된다. 기업 평판이란 기업의 본질과 현실에 대한 소비자가 갖는 태도와 느낌으로써의 기업 이미지(Pharoah, 1982)의 개념을 포괄하면서 기업의 질적 수준에 대한 가치 판단을 반영하고 기업 이미지보다는 장기간에 걸쳐 형성된다(Chun, 2005). 기업 평판은 기업에게 평균 이상의 이익을 가져다주는 전략적 요소이고, 전략적 가치를 제공한다(Dollinger et al, 1997; Rumelt, 1987). 기업 평판은 기업 경쟁력의 중요한 요소이고, 그 경쟁력의 한 척도가 된다(Davies et al, 2003). CSR 성과에 대한 연구로써 CSR과 기업 평판 간의 관계에 대한 많은 연구가 진행되었다(Kim \& Kim, 2009; Aksak et al, 2016; Maden et al, 2012; Park et al, 2014; Verčic and Corić, 2018). 이들 연구 결과에 따르면, CSR 이 기업 평판에 긍정적 영향을 준다. 


\section{2. 사회적 자본}

물적, 재무적, 인적 자본과 같이 사회적 자본도 기업의 중요한 생산요소로 인식되고 있다(Joo et al, 2017). 1980 년대이래로 많은 연구자들은 사회의 구성원으로서의 개인은 물론이고 국가, 사회, 커뮤니티를 대상으로 한 사회적 자본에 대한 연구를 진행해 왔다(Bourdieu, 1986; Coleman, 1988; Putnam et al, 1993). Bourdieu(1986)와 Coleman(1988, 1990)이 사회적 자본의 개념을 정립하여 이론을 구축하였고, Putnam(1993, 1995)은 그 개념을 정치와 문화 영역으로 확장하였다(Kim, 2004). 사회적 자본이란 구성원들 간의 관계구조에서 발생하는 자원들의 집합체라 할 수 있다(Adler \& Kwon, 2002; Nahapiet \& Ghoshal, 1998). 사회적 자본은 개인 또는 집단에게 이용가능한 호의(goodwill)라 할 수 있는데(Adler \& Kwon, 2002), 사회적 관계에 배태된 자본으로 신뢰.규범. 네트워크를 통해 동원된다. Adler and Kwon (2002)에 따르면, 사회 구조가 사회적 자본의 원천인데, 그 구조는 사회적 관계(social relations)시장 관계(market relations)계층 관계(hierarchical relations)로 구분된다. 사회적 자본은 사회적 관계로부터 형성된 자본이며, 사회적 관계는 시장 관계와 계층 관계의 영향을 받는다. 사회적 자본은 인적 네트워크를 통해 조달할 수 있는 자원의 양으로 측정되는 인적 자본과는 구분된다. 사회적 자본이 인적 자본의 가치를 극대화하는데 커다란 영향을 미친다(Lee, 2016). 인적 자본과 가치창출의 관계에서 사회적 자본이 지렛대 역할을 한다. 개인이 갖는 사회적 자본에 따라 인적 자본을 활용하여 가치를 창출하는 것이 다르다(Lee, 2016).

다양한 방식으로 사회적 자본을 분류하고 있는데, Putnam(2000)은 사회적 자본을 연결 사회적 자본(bridging social capita)과 결속 사회적 자본(bonding social capital)으로 구분하였다. 감정적 연결없이 자율적으로 단순히 정보나 새로운 관점을 주고받는 관계인 약한 연대로부터 형성되는 경우는 연결 사회적 자본이라 한다. 반면에 가족이나 친구의 관계와 같은 강한 연대로부터 형성되는 경우는 결속 사회적 자본이라 한다. 구조적 차원, 관계적 차원, 인지적 차원으로 사회적 자본을 분류하기도 한다(Nahapiet \& Ghoshal, 1998). 구조적 사회적 자본(structural dimension of social capital)이란 구성원들 간의 연결 유무와 접근 가능성을 나타내는 네트워크 연결성(network ties)과 연결 패턴으로 연결의 응집력을 의미하는 네트워크 구성(network configuration)을 나타낸다. 관계적 사회적 자본(relational dimension of social capital)은 신뢰·믿음호혜 등을 의미하며. 인지적 사회적 자본(cognitive dimension of social capital)은 비전과 가치의 공유 정도를 의미한다. 구성원들이 네트워크에서 신뢰 관계를 갖고 비전과 가치를 공유함으로써 사회적 자본이 축적된다(주재훈, 신민석, 엄태인, 2014). 세 유형의 사회적 자본은 배타적이라 보다는 상호 연계되어 있다(Nahapiet \& Ghoshal, 1998).
Bhandari and Yasunobu (2009)에 따르면, 사회의 서로 다른 계층에 사회적 자본이 형성되며, 서로 다른 수준에서 분석될 수 있다. 사회적 자본은 마이크로 수준(micro-level), 메조 수준(meso-level), 매크로 수준(macro-level)에서 분석될 수 있다. 가정, 이웃, 사회에서의 개인적 관계에서 분석되는 경우는 마이크로 수준이다. 커뮤니티, 집단, 기관, 조직에 역점을 두고 분석되는 경우는 메조 수준이다. 끝으로 국가나 정치적 환경에 역점을 두고 분석하는 경우는 매크로 수준이다(Bhandari \& Yasunobu, 2009). 여러 분야와 수준에서 사회적 자본에 대한 연구가 진행되어 왔다(Kwon \& Adler, 2014).

\section{3. 연구모형과 연구가설}

\section{1. 연구모형}

기업 평판은 기업 경쟁력 또는 경쟁우위의 핵심요소이다. Kay (1993)는 기업의 경쟁력이란 혁신능력, 내외적 핵심 관계, 평판, 전략적 자산으로 구성된다고 하였다. Vilanova et al. (2009)에 따르면, 성과, 품질, 생산성, 혁신, 명성과 이미지는 기업 경쟁력의 중요한 구성 요소이다. 따라서 기업 평판은 경쟁력을 평가하는 대안으로 이용될 수 있다. 본 연구에서는 기업 평판을 기업 경쟁력 또는 CSR 성과 지표로 이용한다.

기업의 CSR 활동은 직접적으로 기업 평판에 긍정적 영향을 주기도 하며, 사회적 자본을 형성하도록 하고, 이를 통해 기업 평판이 개선되고 경쟁력을 갖게 된다(Joo et al, 2017). Joo et al. (2017)은 한국과 미국의 7 개 기업의 9 명의 경영자들과의 인터뷰를 통해 수집한 자료를 기초로 $<$ Figure 1>의 관계를 분석하였다.

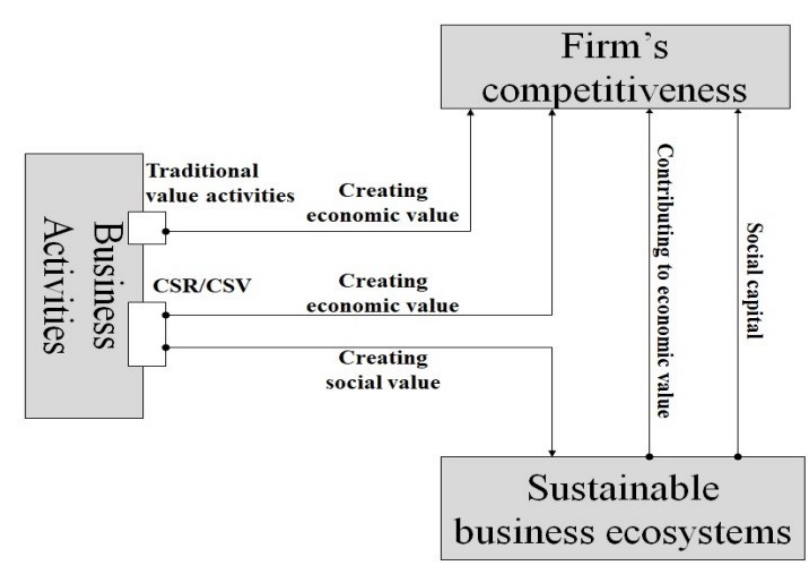

Source: Joo et al. (2017), p. 4.

Figure 1: Relationships between corporate activities, business ecosystems, and corporate competitiveness 
본 연구에서는 CSR, 기업 평판, 사회적 자본에 대한 선행연구와 <그림 $1>$ 을 기반으로 <Figure 2>의 연구모형을 제안한다. CSR 과 기업 성과 간의 관계에 대한 연구에서도 CSR 은 기업에 대한 긍정적 평판에 CSR 이 긍정적 영향을 주는 것으로 나타나고 있다 (Grover et al, 2019; Lee, 2019; Verčic \& Coní, 2018). 선행연구에서 CSR 과 사회적 자본 간에는 상호 영향을 주고 받는 관계가 있는 것으로 나타나고 있다 (Sacconi \& Antoni, 2011; Jha \& Cox, 2015). <Figure 2>에서는 CSR 활동과 기업 평판과의 관계, $\mathrm{CSR}$ 활동이 사회적 자본을 통해 기업 평판에 간접적으로 영향을 주는 관계를 구조방정식 모형으로 나타내고 있다.

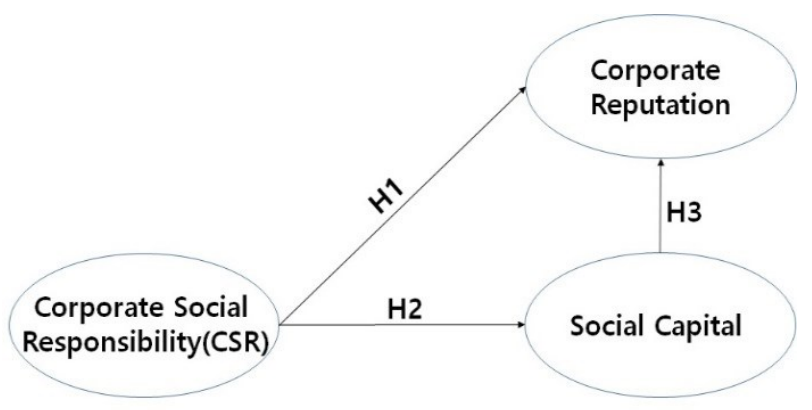

Figure 2: Research model

\section{2. 연구가설}

$\mathrm{Kim}$ and Kim (2009)의 한국과 중국 학생을 대상으로 CSR 활동과 기업 평판 간의 관계에 대한 연구에 따르면, 두 국가 모두에서 CSR 활동이 기업 평판에 긍정적인 영향을 미치는 것으로 나타났다. Choi et al. (2011)은 스타벅스 이용자들을 대상으로 스타벅스의 CSR 활동과 기업 평판 간의 관계를 실증분석하였는데 CSR 은 기업 평판에 긍정적 영향을 미치는 것으로 나타났다. 한국의 소비자들을 대상으로 한 4 가지 유형(경제적, 법률적, 윤리적, 박애적 책임)의 CSR 과 기업 평판 간의 관계를 분석한 연구에서 박애적 책임을 제외한 3 가지 유형의 CSR 이 기업 평판에 유의적인 영향을 미치는 것으로 나타났다(Park et al, 2014). 그 외의 몇몇 연구에서도 지각된 CSR은 기업 평판에 유의적인 긍정적 영향을 미치는 것으로 밝혀졌다(Grover et al, 2019; Lee, 2019; Verčic \& Conić, 2018). 선행연구와 Figure. 2 의 연구모형을 토대로 다음의 연구가설 1 이 도출되었다.

연구가설 1(H1): CSR 활동은 기업 평판에 긍정적 영향을 미친다.

$\mathrm{CSR}$ 과 사회적 자본의 관계에 대해 몇몇 연구가 진행되어 왔는데, CSR 활동이 사회적 자본을 형성에 기여한다는 연구(Sacconi \& Antoni, 2011)와 사회적 자본을 형성하는 것은 물론이고, 이해관계자들의 신뢰와 협력을 강화한다는 연구가 있다(Eccles et al, 2014). CSR 과 기업 평판 간의 상호
영향을 준다는 연구도 있다. 높은 수준으로 사회적 자본이 축적된 지역의 기업이 더 잘 CSR 활동을 수행한다는 연구도 있다(Jha \& Cox, 2015). 선행연구와 Figure 2 의 연구모형을 토대로 다음의 연구가설 2 가 도출되었다.

연구가설 2(H2): 사회적 책임 활동은 사회적 자본에 긍정적 영향을 미친다.

사회적 자본과 기업 평판 간의 관계에 대한 연구를 찾아보기는 어려운 실정이다. Luoma-aho and Vilma. (2013)에 따르면, 기업의 평판은 사회적 자본의 축적을 가능하게 하는 한편, 사회적 자본으로 인해 기업은 좋은 평판을 얻게 된다. Hvižđááková and Urbancikova (2014)의 연구에 따르면, EU 에서 사회적 자본은 기업의 혁신과 경쟁력에 긍정적 영향을 준다. 요르단 은행에서 사회적 자본과 경쟁우위 간의 관계에 대한 Al-Daibat (2017)의 연구에 따르면, 구조적, 관계적, 인지적 사회적 자본 모두가 은행의 경쟁우위(비용, 품질, 유연성, 배송)에 긍정적으로 유의적인 영향을 미친다. Kirkbesoglu(2013)는 터키 경영자의 평판과 사회적 자본의 관계를 소셜 네트워크 분석과 회귀분석 기법으로 실증분석을 수행하였다. 포브스 100 대 기업에 속하는 28 명의 터키기업 경영자들을 표본으로 한 조사에 따르면, 사회적 자본은 경영자의 평판에 유의적인 영향을 준다(Kirkbesoglu, 2013). 한편 기업 평판은 사회적 자본과 기업 경쟁우위 간의 관계에서 매개역할을 한다는 연구도 있다(Wang, 2014). 선행연구와 <그림 2>의 연구모형을 토대로 다음의 연구가설 3 이 도출되었다.

연구가설 3(H3): 사회적 자본은 기업 평판에 긍정적 영향을 미친다.

\section{4. 표본설계와 분석}

\section{1. 변수의 측정}

Table 1 에서는 각 변수의 설문항목과 출처를 나타내고 있다. 각 설문항목은 $\mathrm{CSR}$, 사회적 자본, 기업 평판에 대한 선행연구를 기반으로 본 연구에 맞게 재작성하였다. 설문지에 대한 사전 검토의 과정을 거친 후 최종적으로 3 개 변수의 15 개 설문항목을 리커트(likert) 5 점 척도로 측정하였다.

본 연구는 경주지역에 본사를 두고 있는 한수원이라는 공기업을 대상으로 경주지역 대학에 대한 한수원의 CSR 활동을 대상으로 설문조사를 통해 수집한 자료를 통해 CSR 활동, 사회적 자본, 기업 명성의 관계에 관한 연구모형과 가설을 검증한다. 
Table 1: Questionnaire items

\begin{tabular}{|c|c|c|c|}
\hline Variable & Code & Question item & Source \\
\hline \multirow{7}{*}{$\begin{array}{l}\text { Corporate } \\
\text { Social } \\
\text { Responsibility } \\
\text { (CSR) }\end{array}$} & CSR1 & I think that KHNP supports proactively college students' voluntary activities. & \multirow{7}{*}{$\begin{array}{l}\text { Shin et al. (2016), Verčič and } \\
\text { Corić (2018) }\end{array}$} \\
\hline & CSR2 & $\begin{array}{l}\text { I think that KHNP supports proactively various activities being helpful to college } \\
\text { students' learning. }\end{array}$ & \\
\hline & CSR3 & I think that KHNP supports proactively college students' scholarship. & \\
\hline & CSR4 & $\begin{array}{c}\text { I think that KHNP supports proactively improvement of college education } \\
\text { environments. }\end{array}$ & \\
\hline & CSR5 & I think that KHNP helps proactively college students' welfare. & \\
\hline & CSR6 & I think that KHNP supports proactively college students' practical learning. & \\
\hline & CSR7 & I think that KHNP supports proactively college students' employment. & \\
\hline \multirow{5}{*}{$\begin{array}{l}\text { Perceived Social } \\
\text { Capital (SOC) }\end{array}$} & SOC1 & I think that KHNP contributes to building citizen's solidarity in local community. & \multirow{5}{*}{$\begin{array}{l}\text { Dai et al. (2015), Ellison et al. } \\
\text { (2007), Tang (2016) }\end{array}$} \\
\hline & SOC2 & I think that KHNP contributes to building citizen's trust in local community. & \\
\hline & SOC3 & $\begin{array}{l}\text { I think that KHNP contributes to facilitating citizen's communication in local } \\
\text { community. }\end{array}$ & \\
\hline & SOC4 & I think that KHNP contributes to citizen's open-mindedness in local community. & \\
\hline & SOC5 & I think that KHNP contributes to building citizen's cohesion in local community. & \\
\hline \multirow{3}{*}{$\begin{array}{c}\text { Corporate } \\
\text { Reputation (REP) }\end{array}$} & REP1 & I have a good KHNP image. & \multirow{3}{*}{$\begin{array}{l}\text { Chun (2005), Park et al. } \\
(2014), \\
\text { Ponzi et al. }(2011), \\
\text { Verčič and Ćorić (2018) }\end{array}$} \\
\hline & REP2 & I evaluate KHNP positively. & \\
\hline & REP3 & I think that KHNP is a good company. & \\
\hline
\end{tabular}

\section{2. 분석}

\subsection{1 표본 특성}

설문조사는 2018 년 12 월 20 일부터 2019 년 1 월 21 까지 구글 드라이브를 이용하여 온라인에서 수행되었다. 195 개의 표본을 수집하였다. SPSS 23 을 이용하여 표본 특성에 관한 기술분석과 탐색적 요인분석을 하였다.

Table 2: Demographic characteristics $(n=195)$

\begin{tabular}{|c|c|c|c|}
\hline Classification & Item & Frequency & Percent \\
\hline \multirow{3}{*}{ Gender } & Male & 119 & 61.0 \\
\cline { 2 - 4 } & Female & 76 & 39.0 \\
\hline \multirow{4}{*}{ Student and staff } & Freshman & 10 & 5.1 \\
\cline { 2 - 4 } & Sophomore & 26 & 13.3 \\
\cline { 2 - 4 } & Junior & 26 & 13.3 \\
\cline { 2 - 4 } & Senior & 70 & 35.9 \\
\cline { 2 - 4 } & Staff & 63 & 32.3 \\
\hline
\end{tabular}

구조방정식모형으로 연구가설을 검정하는 데는 Smart PLS 3.0 을 이용하였다. Table 2 에서는 응답자의 특성을 표현하고 있다. 남성의 비율이 $61 \%$ 로 여성보다 높은 편이고, 4 학년 비율이 $36 \%$ 로 가장 높다. 또한 대학의 직원 응답자 비율도 $32 \%$ 이다. 저학년에 비해 고학년일수록
지역사회에 대한 이해가 높다고 볼 수 있어 표본의 선정이 적절하다고 볼 수 있다.

\subsection{2. 신뢰성과 타당성}

SPSS 를 이용하여 탐색적 요인분석을 통해 베리백스 회전을 한 결과는 Table 3 과 같다. 고유값이 10 이상인 3 개의 요인이 도출되었고, 각 요인에서 요인적재값이 0.7 이상이고, 두 번째 요인에는 최대 요인적재값이 376 으로 적은 편이다. 따라서 각 설문항목은 3 개의 요인에 잘 묶이었다.

Table 4 에서 변수의 내적일관성을 측정하는 크론바흐 알파값이 0.7 이상일 때, 신뢰성이 있다고 보는데 3 개 변수 모두에서 0.9 이상이었다(Nunnally \& Berstein, 1994). 또한 3 개 변수 모두에서 $\mathrm{CR}($ Composite Reliability)이 0.9(기준값, 0.7) 이상이고, 평균표본추출값(AVE Average Variance Extracted)이 0.7(기준값 0.5) 이상으로 집중타당성이 있다(Hair et al, 2010). Table 4 에서 대각선 칸의 값은 AVE 의 자승근을 나타내는데, $\mathrm{AVE}$ 의 모든 값이 해당 변수 간의 상관계수를 초과하기 때문에 판별다탕성이 있다.

Table 3: Exploratory factor analysis (Varimax rotation)

\begin{tabular}{|c|c|c|c|c|c|}
\hline Items & CSR & SOC & REP & Eigenvalue & $\begin{array}{c}\text { Cumulative } \\
\text { variance (\%) }\end{array}$ \\
\hline CSR1 & .706 & .376 & & \multirow{2}{*}{9.472} & 34.093 \\
\hline CSR2 & .788 & .347 & & & \\
\hline
\end{tabular}




\begin{tabular}{|c|c|c|c|c|c|}
\hline CSR3 & .838 & .253 & & & \\
\hline CSR4 & .844 & .281 & & & \\
\hline CSR5 & .808 & .319 & & & \\
\hline CSR6 & .794 & .222 & & & \\
\hline CSR7 & .739 & & .298 & & \\
\hline SOC1 & .295 & .849 & & \multirow{5}{*}{1.619} & \multirow{5}{*}{61.392} \\
\hline SOC2 & .335 & .808 & & & \\
\hline SOC3 & & .792 & .353 & & \\
\hline SOC4 & & .774 & .325 & & \\
\hline SOC5 & .355 & .764 & & & \\
\hline REP1 & .280 & & .852 & \multirow{3}{*}{1.049} & \multirow{3}{*}{80.935} \\
\hline REP2 & .270 & & .854 & & \\
\hline REP3 & & .344 & .846 & & \\
\hline
\end{tabular}

Table 4: Reliability and validity

\begin{tabular}{|c|c|c|c|c|c|c|}
\hline & CA & CR & AVE & CSR & SOC & REP \\
\hline CSR & 0.945 & 0.955 & 0.752 & $\mathbf{0 . 8 6 7}$ & & \\
\hline SOC & 0.948 & 0.960 & 0.828 & 0.700 & $\mathbf{0 . 9 1 0}$ & \\
\hline REP & 0.946 & 0.966 & 0.903 & 0.591 & 0.674 & $\mathbf{0 . 9 5 0}$ \\
\hline
\end{tabular}

CA: Cronbach's Alpha, CR: Composite Reliability, AVE: Average Variance Extracted, CSR: Corporate Social Responsibility, SOC: Perceived Social Capital, REP: Corporate Reputation
Table 5 에 나타낸 바와 같이, Heterotrait-Monotrait Ratio (HTMT)가 0.9 이하로 판별타당성이 있는 것으로 나타났다(Garson, 2016).

Table 5: Heterotrait- Monotrait Ratio

\begin{tabular}{|l|l|l|}
\hline & CSR & SOC \\
\hline SOC & 0.738 & \\
\hline REP & 0.624 & 0.710 \\
\hline
\end{tabular}

\subsection{3. 가설검정}

SmartPLS 에서 연구모형의 적합도는 SRMR과 NFI가 주로 이용되는데, 본 연구모형의 경우 $\mathrm{SRMR}=0.044, \mathrm{NF}=0.877$ 로 적합도는 만족스럽다. Figure 3 의 구조방정식 모형의 분석결과에서 사회적 자본의 설명력(독립변수의 매개변수에 대한 분산량을 표현함)을 나타내는 은 0.492 이고, 기업 평판의 설명력을 나타내는 은 0.482 로써 좋은 편이다.

Table 6 에서는 연구가설과 관련된 경로계수와 $\mathrm{t}$ 값 및 유의수준을 의미하는 p 값을 나타내고 있다. 연구가설, $\mathrm{H1}$ 은 유의수준 0.01 에서 채택되었고, 연구가설 $\mathrm{H} 2$ 와 $\mathrm{H} 3$ 은 유의수준 0.001 에서 채택되었다. $\mathrm{CSR}$ 과 기업 평판 간의 관계에서 직접적인 경로에 대한 연구가설은 유의 수준 0.01 에서 채택되었고, 간접적인 경로인 사회적 자본을 통해 $\mathrm{CSR}$ 이 기업 평판에 긍정적 영향을 준다는 연구가설은 유의수준 0.001 에서 채택되었다. 본 연구결과를 통해 CSR 과 기업 평판 간의 관계에 대한 이전의 연구에서는 밝혀지지 않았던 연결고리의 역할이 크다는 것을 알 수 있다.

Table 6: Path coefficients and results of hypothesis testing

\begin{tabular}{|c|c|c|c|c|c|c|c|}
\hline Hypothesis & Path & VIF & Path coefficient & SD & t & p-value & Result \\
\hline H1 & CSR - SOC & 1.000 & 0.234 & 0.074 & 3.179 & $0.002^{* *}$ & Supported \\
\hline H2 & CSR - P REP & 1.963 & 0.700 & 0.052 & 13.567 & $0.000^{* * *}$ & Supported \\
\hline H3 & SOC - P REP & 1.963 & 0.504 & 0.074 & 6.858 & $0.000^{* * *}$ & Supported \\
\hline
\end{tabular}

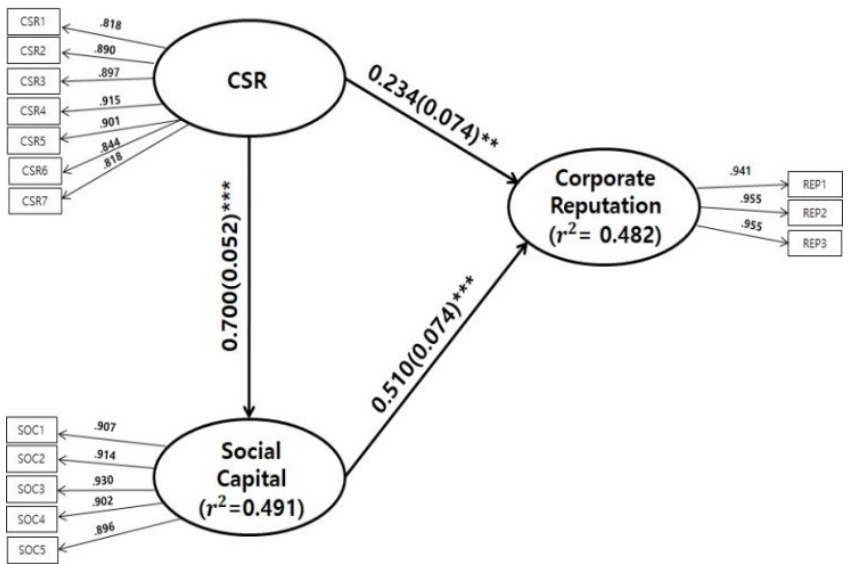

Figure 3: Measurement model and results of analysis

\section{5. 토의 및 결론}

\section{1. 토의}

본 연구에서는 CSR, 사회적 자본, 기업 평판 간의 관계를 구조방정식 모형으로 나타내고, 그들 간의 관계를 한수원이라는 공기업의 사례를 통해 지역 대학의 학생들과 직원들이 지각하는 바를 기반으로 3 개의 연구가설을 검증하였다. 연구가설을 검증한 결과, 모든 연구가설이 채택되었다. 즉, 한수원의 CSR 활동이 기업 평판에 긍정적 영향을 준다. 한수원의 지역사회(대학)를 위한 CSR 활동이 사회적 자본 형성에 기여하고, 이를 통해 기업의 평판이 향상된다. 달리 말하자면, 한수원의 
CSR 활동을 높게(또는 긍정적으로) 평가할수록 그 기업에 대한 평판도 더욱 긍정적이었고, 그 기업이 사회적 자본을 형성하는데 기여도가 높다고 지각한다. 한수원의 사회적 자본 형성에 대한 기여도가 높다고 지각한 응답자일수록 한수원에 대한 평판이 좋았다.

$\mathrm{CSR}$ 과 그 성과 또는 기업 경쟁력 간의 관계에 대한 대부분의 연구에서는 CSR 활동이 그 성과에 미치는 직접적인 영향을 고찰해 왔다. 그 연구 결과도 모두가 일치하는 것은 아니었다. 본 연구는 CSR 와 그 성과 간의 관계에서 고려되지 못했던, 간접적 관계를 분석하였다. 즉, $\mathrm{CSR}$ 은 기업 평판에 직접적으로 영향을 주는 것보다는 도리어 사회적 자본을 통해 간접적으로 더 강한 영향을 미치는 것을 입증하였다. 이는 $\mathrm{CSR}$ 활동이 궁극적으로는 사회에 공헌하는 것을 넘어서 사회적 자본의 축적에 기여하고, 이를 통해 기업 평판을 개선하는 데 도움이 된다는 것을 뜻한다. 따라서 CSR 의 정당성이 더욱 확보되어 향후에 기업의 전략적 의사결정에 도움이 될 수 있을 것이다.

\section{2. 함의와 연구 한계}

본 연구의 이론적 함의는 다음과 같다. 기존의 연구는 CSR 과 기업 평판 또는 성과(또는 경쟁력, 경쟁우위)와의 직접적인 관계만을 고려하였다. 즉, $\mathrm{CSR}$ 이 기업 평판에 영향을 주는 또 다른 경로를 간과하였다. 본 연구는 사회적 자본을 매개변수로 도입하여 CSR 과 기업 평판 간의 긍정적 관계를 규명하였다. 따라서 본 연구모형은 CSR과 그 성과를 분석하는데 다양한 형태로 확장 적용될 수 있다. 예를 들어, 기업 평판 대신 다른 여러 성과 변수를 이용할 수 있다.

본 연구의 실무적 함의는 다음과 같다. 첫째로 기업의 경영자들에게는 CSR 활동을 통한 투자에 대한 회수가 직접적이라 보다는 장기적 관점에서 사회적 자본을 축적하여 평판을 통해 이루어진다는 것을 인식할 수 있는 기회를 제공한다. 둘째로 본 연구 결과는 기업 경영자들에게 $\mathrm{CSR}$ 과 사회적 자본, 나아가 고객 충성도 간의 새로운 연계에 대한 통찰력을 제공한다. 비즈니스에서의 영성(spintuality)에 대한 다양한 관점에서의 연구가 진행되어 오고 있다(Samul, 2020). 지성과 감성 마케팅을 넘어서 영성 마케팅(spinitual marketing)도 고객의 충성도를 높이는데 기여한다(Costa, 2018; Kotler et al, 2010; Rini \& Absah, 2017). 영성자본은 사회적 자본의 일부로써 물적 자본 및 인적 자본과 더불어 기업 활동의 중요한 자원으로 인식되고 있다(Zymonik \& Dobrowolska, 2015). 미래사회와 소비자 인식의 변화, 지속가능한 발전의 관점에서 볼 때, 고객의 영성을 이끌어내는 비즈니스 활동이 기업 경쟁력의 원천으로 인식되고 있다. 기업은 제품 그 자체를 넘어서 $\mathrm{CSR}$ 을 통해 고객의 영성을 이끌어내고, 사회적 자본을 축적한다. CSR 을 통해 사회적 자본을 구축하는 토대를 마련한
기업은 더 잘 고객의 마음 속 깊은 곳을 감동시킬 수 있어 궁극적으로는 고객의 충성도를 높일 수 있다.

선행연구에서도 CSR 이 기업 성과 또는 경쟁력이나 기업 평판에 긍정적인 영향을 준다는 것이 밝혀진 바 있다. 그러나 사회적 자본이 CSR과 기업 평판 간에 매개역할을 하는가에 대한 연구는 수행된 바가 없다. 따라서 본 연구결과가 공헌하는 바는 CSR 이 기업 평판에 직접적으로 영향을 주는 것 외에 사회적 자본을 통해 간접적으로 영향을 주는 경로를 발견하였다는 점이다.

본 연구의 결과를 일반화하는 데는 한계가 있다. 그 첫째는 한수원이라는 하나의 사례 기업을 통해 분석하였다는 점이다. 둘째는 구조방정식 모형과 가설을 검정하기 위해 사례 기업의 CSR 활동을 경험하고 있는 지역 대학의 학생들과 직원만을 대상으로 자료를 수집하였다는 것이다. 따라서 향후에 본 연구모형과 연구가설을 다양한 기업을 대상으로 표본을 수집하여 분석할 필요가 있다.

\section{References}

Adler, P.S. \& Kwon, E. (2002). Social capital: Prospects for a new concept. Academy of Management Review, 27(1), 17-40.

Ahmadian, A. \& Khosrowpour, S. (2017). Corporate social responsibility: Past, present, and success strategy for the future. Journal of Service Science, 10(1), 1-11.

Aksak, E. O., Ferguson, M. A., \& Duman, S. A. (2016). Corporate social responsibility and CSR fit as predictors of corporate reputation: A global perspective. Public Relations Review, 42(1), 79-81.

Al-Daibat, B. (2017). The role of social capital in enhancing competitive advantage. International Journal of Business and Management Invention, 6(4), 66-78.

Bhandari, H. \& Yasunobu, K. (2009). What is social capital? A comprehensive review of the concept. Asian Journal of Social Science, 37, 480-510.

Bourdieu, P. (1986). The forms of capital, In J. Richardson (Ed.), Handbook of Theory and Research for the Sociology of Education (pp. 241-258), New York, Greenwood.

Carey, S., Lawson, B., \& Krause, D. (2011). Social capital configuration, legal bonds and performance in buyer-supplier relationships. Journal of Operations Management, 29(6), 561576.

Carroll, A. B. (1979). A three-dimensional conceptual model of corporate performance. The Academy of Management Review, 4(4), 497-505.

Carroll, A. B. (1991). The pyramid of corporate social responsibility: Toward the moral management of organizational stakeholders. Business horizons, 34(4), 39-48.

Cho, Y., Chung, J., \& Chun, S. (2019). How do retailers' CSR business activities affect customers in Korea? Journal of Distribution Science, 17(10), 5-15.

Choi, S., You, G., \& Kown, Y. (2011). The Effects of CSR activities of Starbucks corporate on reputation, social connectedness, and customers' purchasing intention. Journal of Tourism and Leisure Research, 23(2), 97-116.

Chun, R. (2005). Corporate reputation: meaning and measurement. 
International Journal of Management Reviews, 7(2), 91-109.

Cochran, P. L. (2007). The evolution of corporate social responsibility. Business Horizons, 50, 449-454.

Coleman, J. S. (1988). Social capital in the creation of human capital. American Journal of Sociology, 94, S95-120.

Coleman, J. S. (1990). Foundations of Social Theory. Cambridge, MA: Harvard University Press.

Costa, D. (2018). Spiritual marketing and its influence on consumer purchase intentions of XYZ Company, UAE. 15th International Conference on Business Management (ICBM 2018), 832-852.

Dai, W., Mao, Z., Zhao, X., \& Mattila, A. S. (2015). How does social capital influence the hospitality firm's financial performance? The moderating role of entrepreneurial activities. International Journal of Hospitality Management, 51, 42-55.

Dollinger, M. J., Golden, P. A., \& Saxton T. (1997). The effect of reputation on the decision to joint venture. Strategic Management Journal, 18(2), 127-140.

Eccles, R. G., Ioannou, I., \& Serafeim, G. (2014). The impact of corporate sustainability on organizational processes and performance. Management Science, 60, 2835-2857.

Ellison, N. B., Steinfield, C., \& Lampe, C. (2007). The benefits of Facebook "friends": Social capital and college students' use of online social network sites. Journal of Computer-Mediated Communication, 12(4), 1143-1168.

Fombrun, C. J., \& Van Riel, C. (1997). The reputational Landscape. Corporate Reputation Review, 1, 5-13.

Fombrun, C.J., \& Rindova, V. (1996). Who's tops and who decides? The social construction of corporate reputations. New York University, Stern School of Business, Working Paper.

Garson. G. D. (2016). Partial least squares: regression \& structural equation models. Retrieved January 12, 2020 from https://www.smartpls.com/resources/ebook_on_pls-sem.pdf

Grover, P., Kar, A.K., \& Ilavarasan, P.V. (2019). Impact of corporate social responsibility on reputation - Insights from tweets on sustainable development goals by CEOs. International Journal of Information Management, 48, 39-52.

Hair, J.F., Black, W.C., Babin, B.J., \& Anderson, R.E. (2010). Multivariate Data Analysis. Seventh Edition. Prentice Hall, Upper Saddle River, New Jersey.

Hillman, A. J., \& Keim, G. D. (2001). Shareholder value, stakeholder management, and social issues: What's the bottom line? Strategic Management Journal, 22(2), 125-139.

Hvižd'áková, I., \& Urbancikova, N. (2014). The level of social capital, innovation and competitiveness in the countries of the European Union (EU). European Spatial Research and Policy, 21(1), 123-136.

Jeon, H., Kim, Y., \& Youn, M. (2019). Effects of CSR Activities on Business Performance of Logistics Firms. Journal of Distribution Science, 17(12), 23-32.

Jha, A., \& Cox, J. (2015). Corporate social responsibility and social capital. Journal of Banking \& Finance, 60, 252-270.

Joo, J., Eom, M.T., \& Shin, M.M. (2017). Finding the missing link between corporate social responsibility and firm competitiveness through social capital: A business ecosystem perspective. Sustainability, 9(5), 1-22, doi:10.3390/su9050707

Joo, J., Shin, M. M., \& Eom, M. T. (2014). Business ecosystems as a new source of competitiveness and a role of social capital.
The Journal of Information Systems, 23(4), 93-117.

Kay, J. (1993), Foundations of Corporate Success (Oxford, Oxford University Press).

Kim, H, \& Kim, H (2009). The effect of CSR on corporate reputation: Comparing Korean public's perceptions with Chinese public's. The Korean Journal of Advertising and Public Relations, 11(4), 64-92.

Kim, S. (2004). A critique of Bourdieu's, Coleman's and Putnam's concept of social capital. Korean Journal of Sociology, 38(6), 63-95.

Kim, S., \& Lee, K. (2013). Corporate social responsibility (CSR) in accounting : Review and future direction. Korean Journal of Business Administration, 26(9), 2397-2425.

Kirkbesoglu, E. (2013). The impact of social capital on managerial reputation. Procedia - Social and Behavioral Sciences, 99, 439-445.

Kotler, P., Kartajaya, H., \& Setiawan, I. (2010). Marketing 3.0: From Products to Costumers to the Human Spirit. John Wiley \& Sons, New Jersey.

Kwon, S., \& Adler, P.S. (2014). Social capital: Maturation of a field of research. Academy of Management Review, 39(4), 412-422.

Lee, J. (2019). A study on consumer value and corporate social responsibility distribution activities. Journal of Distribution Science, 17(4), 17-26.

Lee, K. (2016). Social capital and human capital. Retrieved January 12, 2020 from

https://cba.snu.ac.kr/ko/sblcolumn?mode=view\&bbsidx $=77942$

Lim, S., \& Park, B. (2018). An analysis of the relationship between the CSR activities of public enterprise and social reliability: Focusing on authenticity and appropriateness of the CSR activities of public enterprise. The Korean Journal of Local Government Studies, 21(4), 411-435.

Luoma-aho, V. (2013). Corporate reputation and the theory of social capital. The Handbook of Communication and Corporate Reputation. 279-290. 10.1002/9781118335529.ch24.

Maden, C., Arikan, E., Telci, E. E., \& Kantur, D. (2012). Linking corporate social responsibility to corporate reputation: A study on understanding behavioral consequences. Social and Behavioral Sciences, 58, 655-664.

McWilliams, A., Siegel, D. S., \& Wright, P. M. (2006). Corporate social responsibility: Strategic implications. Journal of Management Studies, 43(1), 1-18.

Minor, D., \& Morgan, J. (2011). CSR as reputation insurance: Primum non nocere. California Management Review, 53(3), 40-59. Retrieved from http://nrs.harvard.edu/urn3:HUL.InstRepos:22836595

Nahapiet, J., \& Ghoshal, S. (1998). Social capital, intellectual capital, and organizational advantage. Academy of Management Review, 23(2), 242-266.

Nguyen, T. H., \& Tu, V. B. (2019). Social responsibility, organizational commitment, and organizational performance: Food processing enterprises in the Mekong River Delta. Journal of Asian Finance, Economics and Business, 7(2), 309316.

Nunnally, J. C., \& Bernstein, I. H. (1994). Psychometric theory, 3rd ed., McGraw-Hill, New York. 
Park, A. (2019). A study on the structural relationship between quality of medical service, perceived risk, reputation and customer satisfaction in small and medium hospitals. International Journal of Industrial Distribution \& Business, 10(4), $67 \sim 76$.

Park, J., Lee, H., \& Kim, C. (2014). Corporate social responsibilities, consumer trust and corporate reputation: South Korean consumers' perspectives. Journal of Business Research, 67(3), 295-302.

Pharoah, N. (1982). Corporate image research in the brewing industry or from red revolution to country goodness in ten years. Journal of the Market Research Society, 24(3), 240-256.

Ponzi, L. J., Fombrun, C. J., \& Gardberg, N. A. (2011). RepTrak $^{\mathrm{TM}}$ pulse: Conceptualizing and validating a short-form measure of corporate reputation. Corporate Reputation Review, 14(1), 15-35.

Putnam, R. (1993). Making Democracy Work. Princeton: Princeton University Press.

Putnam, R. (1995). Bowling alone: America's declining social capital. Journal of Democracy, 6(1), 65-78.

Rini, E. S., \& Absah, Y. (2017). Rational, emotional and spiritual marketing strategies in Shariah banking in Medan, Indonesia. Banks and Bank Systems, 12(2), 68-77. doi:10.21511/bbs. 12(2).

Rumelt, R. P. (1987). Theory, strategy and entrepreneurship. In The Competitive Challenge: Strategies for Industrial Innovation and Renewal, Teece D (ed.). Ballinger, Cambridge, MA; 137-157.

Sacconi, L., \& Giacomo D. A. (2011). Social Capital, Corporate
Responsibility, Economic Behaviour and Performance, Palgrave MacMillan, New York, NY.

Samul, J. (2020). Spiritual leadership: Meaning in the sustainable workplace. Sustainability, 12, 267, 1-16

Sethi, S. P. (1975), Dimensions of Corporate Social Performance: An Analytical Framework, 17(3), 58-64.

Shin, I., Hur, W., \& Kang, S. (2016). Employees' perceptions of corporate social responsibility and job performance: A sequential mediation model. Sustainability, 8(463), 1-12

Tang, T. (2016). Making innovation happen through building social capital and scanning environment. International Journal of Hospitality Management, 56, 56-65.

Verčič, A. T., \& Ćorić, D. S. (2018). The relationship between reputation, employer branding and corporate social responsibility. Public Relations Review, 44(4), 444-452.

Vilanova, M., Lozano, J. M., \& Arenas, D. (2009). Exploring the nature of the relationship between CSR and competitiveness. Journal of Business Ethics, 87, 57-69.

Wang, C. (2014). How relational capital mediates the effect of corporate reputation on competitive advantage: Evidence from Taiwan high-tech industry. Technological Forecasting \& Social Change, 82, 167-176.

Wartick, S. L., \& Cochran, P. L. (1985). The evolution of the corporate social performance model. Academy of Management Review, 10, 758-769.

Zymonik, Z., \& Dobrowolska, A. (2015). Spiritual capital as the fourth capital in a TQM organization. Zarzadzanie $i$ Finanse Journal of Management and Finance, 13(2), 147-155. 